\title{
Re-design for change: environmental and financial assessment of a dynamic renovation approach for residential buildings
}

\author{
A. Paduart ${ }^{1}$, W. Debacker ${ }^{2}$, N. De Temmerman ${ }^{3}$, W. P. De Wilde ${ }^{1}$ \\ \& H. Hendrickx ${ }^{3}$ \\ ${ }^{I}$ Department of Mechanics of Materials and Construction, \\ Vrije Universiteit Brussel, Belgium \\ ${ }^{2}$ VITO, Flemish Institute for Technological Research, Mol, Belgium \\ ${ }^{3}$ Department of Architectural Engineering, \\ Vrije Universiteit Brussel, Belgium
}

\begin{abstract}
Existing residential buildings and their daily use are unmistakably influencing the rational consumption of our worldwide natural resources. This observation has led to global renovation regulations, mainly focusing on the reduction of energy consumption caused by occupation. However, equally important are the future environmental and financial impacts of current renovation interventions. Indeed, when minimising the heating energy demand, the main future energy savings will shift towards the life cycle of building materials. Since building conditions change over time, buildings have to be re-designed today to enable future transformation without taking part in further environmental degradation.

Therefore, renovation measures cannot introduce the same 'static' building materialisation as the initial building design, which did not anticipate on future unpredictable need for upgrade and change which we are facing today. This paper evaluates the environmental and financial benefits and drawbacks of redesign introducing reuse strategies, considering not only initial but also future life cycle impacts. An assessment was made for a typical building layer, comparing conventional renovation with design for disassembly (DfD) re-design. Keywords: renovation, environmental and financial assessment, 4D design, reuse.
\end{abstract}




\section{Introduction}

\subsection{The burden of existing residential buildings}

The world of today is facing the environmental impacts of our short building vision: lack of integrated life cycle design in conventional building design has contributed to the current environmental degradation. A large amount of the current European building stock was designed and constructed in a time where fossil fuels were cheap and abundant and global warming was unheard of $[1,2]$. As a result, fossil fuels have been used very inefficiently in constructions predating the oil-crisis, explaining their excessive energy and material consumption in the present-day context.

Renovation practice of today therefore focuses on reduction of energy use during occupation of residential buildings. The main objective is to create lower energy consuming buildings, by enhancing the insulation level and introducing the most energy efficient heating, cooling and ventilation systems available today. Despite the fact that these interventions have high significance in the current context, equal importance should be given to the long-term effects of renovation interventions. When the energy demand of buildings during the operation phase is minimised, any future savings on resource demand will shift towards the remaining life cycle phases of the building. Adaptation, maintenance and end-of-life processes during the life cycle of buildings, relating to inherent building materials and their design, then become of major importance [3, 4].

Therefore, the scope of the current renovation practice needs to be enlarged integrating a long term-vision that minimises the use of natural resources and the building waste stream not only today, but also in the future.

\subsection{Alternative re-design for change}

In this framework it is crucial to assess both initial and future environmental and financial life cycle impacts, when comparing current renovation to alternative renovation initially taking the remaining life cycle of buildings into account.

A dynamic re-design approach of existing residential buildings is selected as alternative to current renovation practice. To reduce the future environmental and financial impact of buildings, the dynamic re-design approach supports future need for change, upgrade and reversibility by using 4-Dimensional design principles [5]. Four-dimensional design strategies reduce the life cycle impact of buildings by incorporating reuse strategies applied to three design levels building material, building component and building level [6]. The aim of these reuse strategies is to reduce as well material and energy demand during use, as to minimise the building waste fractions at the end of life of buildings. Therefore, Design for Deconstruction and Design for Disassembly (DfD) are introduced for re-design of buildings at building component and material level. 


\subsection{Need for an integrated evaluation methodology}

Building solutions designed according to dynamic re-design have another life cycle behavior in financial and environmental terms than conventional design. Deconstruction and disassembly strategies clearly imply atypical assembly techniques and material choices compared with conventional design. The initial financial cost and environmental impact for such building solutions are higher, but life cycle assessment can quantify the environmental and financial benefits and drawbacks of reuse potential and deconstruction advantages compared to demolition, over an entire building life span.

The evaluation methodology in this paper departs from an integrated life cycle approach, assessing the environmental impact of building renovation and its financial consequences, from raw material extraction until waste treatment at the end of life of the building.

The following paragraphs describe the different parts of the integrated assessment approach, i.e. environmental impact assessment using Life Cycle Assessment (LCA) and financial cost evaluation using Life Cycle Costing (LCC). Hereafter, the assessment of a refurbished building layer is illustrated with a variable need for alteration over the building life cycle, i.e. the internal wall partitioning, using the integrated assessment approach.

\section{An integrated environmental and financial evaluation}

\subsection{Building life cycle phases}

The aim is to evaluate the environmental impacts and the financial cost over the whole life cycle of the dwelling, meaning that not only the initial situation is evaluated, but also the maintenance phase and at the end-of-life phase of the building and its components. The environmental assessment is expressed in impacts, the financial assessment expressed in costs.

The phases summarised in Figure 1 are considered in the financial and environmental life cycle assessment:

- Production phase: production of the building materials, including transport;

- Construction phase: transport to the building site, assembly of the (re)construction;

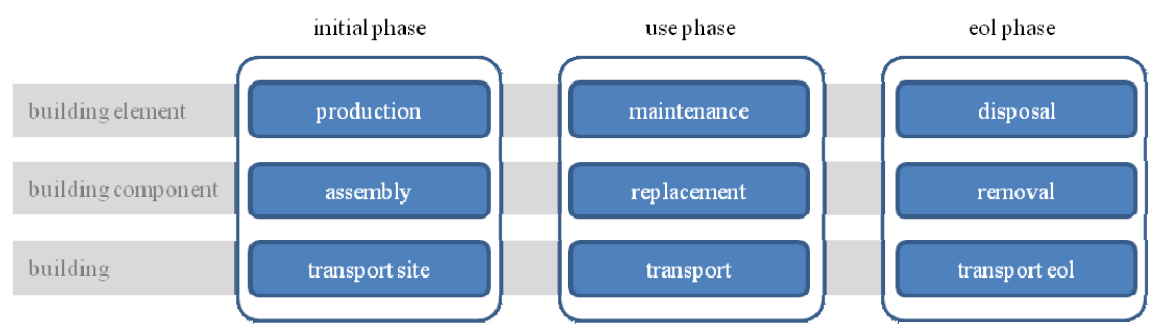

Figure 1: Representation of life cycle inputs/outputs of buildings. 
- Use phase: maintenance, repair and replacement of building products, including transport;

- End of life phase: removal (separation, reuse, deconstruction, demolition) and end-of-life treatment of building materials (recycling, incineration, and landfill), including transport.

\subsection{Integrated life cycle assessment}

To assess (re)designed buildings according to deconstruction and disassembly, alternative reuse and deconstruction loops are inserted in the environmental and financial life cycle evaluation. The life cycle "Financial costs (F)" and "Environmental impacts (E)", occurring during the initial phase, use phase and EoL phase of buildings, are generalised as "impacts" (I) in the next expression:

$$
L C I=\sum_{\mathrm{i}=0} \sum_{\mathrm{a}}^{\mathrm{c}} \mathrm{I}_{\text {in }}+\sum_{\mathrm{i}=1}^{\mathrm{n}=\mathrm{t}-1} \sum_{\mathrm{a}}^{\mathrm{c}} \mathrm{I}_{\mathrm{use}}+\sum_{\mathrm{i}=\mathrm{t}} \sum_{\mathrm{a}}^{\mathrm{c}} \mathrm{I}_{\text {eol }}
$$

with:

LCI: $\quad$ life cycle impact

$\mathrm{i}, \mathrm{j}, \ldots, \mathrm{t}: \quad$ year $($ from $i=0$ until $i=t)$

$\mathrm{a}, \mathrm{b}, \mathrm{c}$ : building material, building component and building level

$\mathrm{I}_{\text {in }}: \quad$ initial impact (year $=0$ )

I $I_{\text {use: }} \quad$ summed impacts during the use phase

$\mathrm{I}_{\mathrm{eol}}$ : $\quad$ summed impacts at the end-of-life phase (year=t)

As represented in Figure 1, the periodic interventions during the use phase can be classified under material, component and building level interventions, so Expression (1) becomes:

$$
\begin{aligned}
L C I=\left(\mathrm{I}_{0, \mathrm{PROD}}+\right. & \left.\mathrm{I}_{0, \mathrm{ASS}}+\mathrm{I}_{0, \mathrm{TR} \text { constr }}\right)+\left(\sum_{i=1}^{n=t-1} \mathrm{I}_{\mathrm{MT}}+\mathrm{I}_{\mathrm{REPL}}+\mathrm{I}_{\mathrm{TR}}\right) \\
& +\left(\mathrm{I}_{0, \mathrm{DISP}}+\mathrm{I}_{0, \mathrm{REMOV}}+\mathrm{I}_{0, \mathrm{TR} \text { eol }}\right)
\end{aligned}
$$

with:

I 0 ,PROD: material production

I мт: total maintenance

$\mathrm{I}_{0, \mathrm{DISP}}$ : final disposal of materials (recycling, landfill, incineration)

$\mathrm{I}_{0, \mathrm{AsS}}$ : assembly labour

$\mathrm{I}_{\mathrm{REPL}}$ : total replacement labour

$I_{0, \text { REMOV: }}$ removal labour (demolition or deconstruction costs)

$\mathrm{I}_{0, \mathrm{TR}}$ site transport from production site to construction site

$\mathrm{I}_{\mathrm{TR}}$ : total transport during the building use phase

I 0 ,TR eol: transport from demolition/deconstruction site to sorting/disposal site 
For all replacements of building elements, due to both technical failure of components as well as alterations of the entire building layer, the second term in Equation (2) becomes:

$$
\begin{aligned}
\sum_{i=1}^{n=t-1}\left(I_{M T}+I_{R E P L}\right. & \left.+I_{T R}\right) \\
= & \sum_{\substack{i=1 \\
n=t-1}}^{n=t-1}\left(\mathrm{I}_{0, \mathrm{DISP}}+\mathrm{I}_{0, \mathrm{PROD}}\right)+\sum_{i=1}^{n=t-1}\left(\mathrm{I}_{0, \mathrm{REMOV}}+\mathrm{I}_{0, \mathrm{ASS}}\right) \\
& +\sum_{i=1}^{n}\left(\mathrm{I}_{0, \mathrm{TR} \text { eol }}+\mathrm{I}_{0, \text { TR constr }}\right)
\end{aligned}
$$

In this equation, $\mathrm{I}_{0, \mathrm{REMOV}}$ is equal to:

- $\quad \mathrm{I}_{0, \mathrm{DEMOL}}$, if the component is non-Dfd designed;

- $\quad I_{0, \text { DECONSTR }}$, if the component is Dfd designed.

For non-DfD designed building components, the replacement of a building element will affect the adjacent building elements, and therefore, equation (3) is also being applied for the adjacent elements for individual building element replacement.

In the case of DfD solutions, surrounding building elements can be disassembled to replace the failing building element, and can hereafter be reassembled in place. Therefore, for these building elements, the second term in Equation (2) becomes:

$$
\sum_{i=1}^{n=t-1}\left(I_{M T}+I_{R E P L}+I_{T R}\right)=\sum_{i=1}^{n=t-1}\left(\mathrm{I}_{0, \mathrm{DISASS}}+\mathrm{I}_{0, \mathrm{RE}-\mathrm{ASS}}\right)
$$

with:

$$
\begin{array}{ll}
\mathrm{F}_{0, \mathrm{DISASS}} & \text { disassembly of the building materials } \\
\mathrm{F}_{0, \mathrm{RE}-\mathrm{ASS}} & \text { re-assembly of the building materials } \\
\mathrm{F}_{0, \mathrm{DEMOL}} & \text { demolition of the building components } \\
\mathrm{F}_{0, \mathrm{DECONSTR}} & \text { deconstruction of the building components }
\end{array}
$$

These expressions can be used for both financial and environmental assessment. Specific implementation of both is discussed in the following paragraph.

\subsection{Financial cost evaluation}

\subsubsection{Discounting}

Because currency is subject to inflation and has the ability to earn interest, it is worth more today than currency tomorrow. Discounting determines how much less currency is worth in the future, and is essential to make the financial evaluation over a total life cycle. 
The discount rate ' $d$ ' defined as 'the factor reflecting the time value of money that is used to convert cash flows occurring at different times to a common time' [7], in this study is assumed to be equal to the interest rate for bank loans $(2 \%)$.

\subsubsection{Present value}

The present value of future costs can be defined as 'the amount of money that would need to be saved today, at a (nominal) interest rate $r$, in order to have the money available to meet the future cost $\left(C_{t}\right)$ at the time when it is predicted to occur (after t periods)'[7]. By discounting all occurring costs at different times during the building life span become comparable and can be aggregated into a total present value.

\subsection{Environmental impact assessment}

\subsubsection{LCA method}

Although weighting the environmental effects to calculate a single score is not advised by ISO 14040 [8], it enables to make a comprehensible comparison between alternatives. However, the single score result should not be considered without assessing the unweighted normalised scores. The weighting factors are based on eco-indicator 99, a transparent impact assessment method that expresses the environmental impact in three environmental effects: human health, quality of ecosystems and depletion of resources [9], expressed in Points (Pt).

\subsubsection{The construction detail: the key for reuse and adaptation}

The number of replacements of building elements depends on the global building service life or the service life of the building layer in which the building element is assembled. For example, when wall partitioning needs spatial reconfiguration, the entire conventional wall needs to be disposed and replaced. In this case, replacements of the building elements depend on the service life of the wall layer, and not of the global building service life. Building elements with reuse design and flexible connections however, can be deconstructed and re-assembled in the new wall assembly using the same building elements. This means that the replacement in this case is depending on the global service life of the building.

The connection type is identified as a key parameter for replacements [10]. A fixed connection causes redundant waste production when replacing a specific building element, since adjacent elements will have to be removed as well. Contrary, flexible connections allow non-destructive replacements of only the failing building elements. Therefore, the flexibility of the connection for each building element in this study is determined for each building assembly, and is taken into account in the calculations of the replacements.

An assessment is made for wall assemblies over a number of building scenarios possibly taking place during the life cycle of a building. The amount and the category of required repairs, replacements and alterations are defined for each building level. The environmental and financial impacts of these alterations are summed with the initial impact and the end-of-life impact for a determined period of life cycle analysis. 


\section{Dynamic versus static building layers}

\subsection{Building layer: internal wall partitioning}

In older apartment buildings the internal wall partitioning is often subject to renovation due to increasing comfort standards of dwellings. The small-format interior layouts and non adaptable typologies of the apartments are no longer suitable for current users. Thermal and acoustic performance also needs upgrading according to the current living standards.

However, it is dependent on the design approach if the environmental and financial load of the interventions is reasonable, today and in the future. The first compared assembly is designed as a "finished" static product that needs demolition when adaptation needs emerge. The latter is designed as an assembly of separated functions that can be detached and re-adjusted, relocated or reused.

\subsubsection{Functional unit}

A functional unit is used to make an objective comparison between wall assemblies. Minimum criteria are set up for the internal wall building layer relating to thermal and acoustic performance and fire resistance and finishing. The functional unit is used for both environmental impact assessment and financial cost analysis, expressed in $1 \mathrm{~m}^{2}$.

\subsubsection{Scenarios}

Buildings are complex artefacts with long service lives compared to other products, explaining the high uncertainty about their service lives. Therefore building scenarios are formulated with varying service lives at all building levels, represented in Table 1. The values for the estimated service life of the components (ESLC) are calculated using the Factor method outlined in ISO 15686-1 [11] using a minimum, typical and maximum life expectancy distribution to consider the most extreme values.

Table 1: $\quad$ Service life scenarios of the building.

\begin{tabular}{lccc}
\hline Scenarios & Building & Building Layer & ESLC \\
\hline reference scenario & $60 \mathrm{y}$ & $30 \mathrm{y}$ & typical \\
\hline short building service life & $30 \mathrm{y}$ & & \\
long building service life & $90 \mathrm{y}$ & & \\
short building layer service life & & $15 \mathrm{y}$ & \\
long building layer service life & & $60 \mathrm{y}$ & \\
short component service life & & & minimum \\
long component service life & & & maximum \\
\hline
\end{tabular}

\subsection{Environmental and financial life cycle assessment}

\subsubsection{Wall types}

Three types of internal walls are analysed: plastered masonry walls (clay bricks, sand lime bricks, cellular concrete blocks and expanded clay blocks), dry walls 


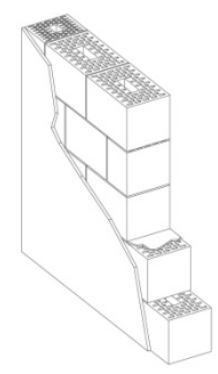

masonry walls

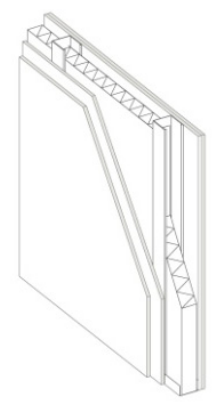

dry walls

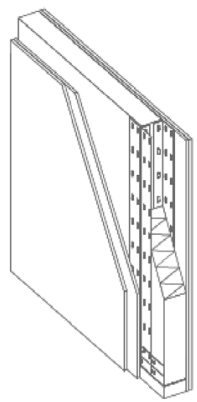

DfD walls

Figure 2: Wall types for assessment.

with gypsum plasterboard (metal studs and wooden frame) and Dfd designed walls (steel frame, aluminium frame and wooden frame).

DfD designed walls aim to extend the service life of the used building elements. This means that for the DfD wall assembly the material choice is crucial to enable these initial intents. The chosen materials are resistant to multiple deconstruction and reconfiguration, have a long technical service life to make reuse viable and enable reversible connections.

Steel, aluminium or wooden prefabricated frames are used with wood-based boarding that can be erected as semi-finished assemblies, and can be deconstructed to base elements with capacity for reuse or transformation to other building products. Special attention is given to the detailing using tolerances and rubber strips to ensure satisfactory thermal and acoustic performance.

\subsection{Results}

\subsubsection{Service life scenario}

The summarised results for two service lives scenarios of the internal wall are represented in Figures 3 and 4. On the left of the graphs, the results are shown for wall service lives varying between 15 and 60 years for alternative wall solutions. On the right, the extreme scenarios for the estimated service life the components are shown. Both the financial ( $L C F)$ and environmental ( $L C E)$ life cycle assessment graphs indicate comparable results for the differences between conventional walls and DfD designed walls.

The results reveal that although DfD solutions for internal walls have a higher financial and environmental initial impact than conventional solutions, the life cycle impact during the remaining life can be beneficial or disadvantageous depending on the considered building scenario. The elevated initial impact can be explained by the higher initial impact of specifically chosen building materials and building techniques needed for DfD construction.

The service life of both the building layer (in this case, the internal partitioning) and of the components has been identified as a key parameter for the financial and environmental viability of DfD design. 


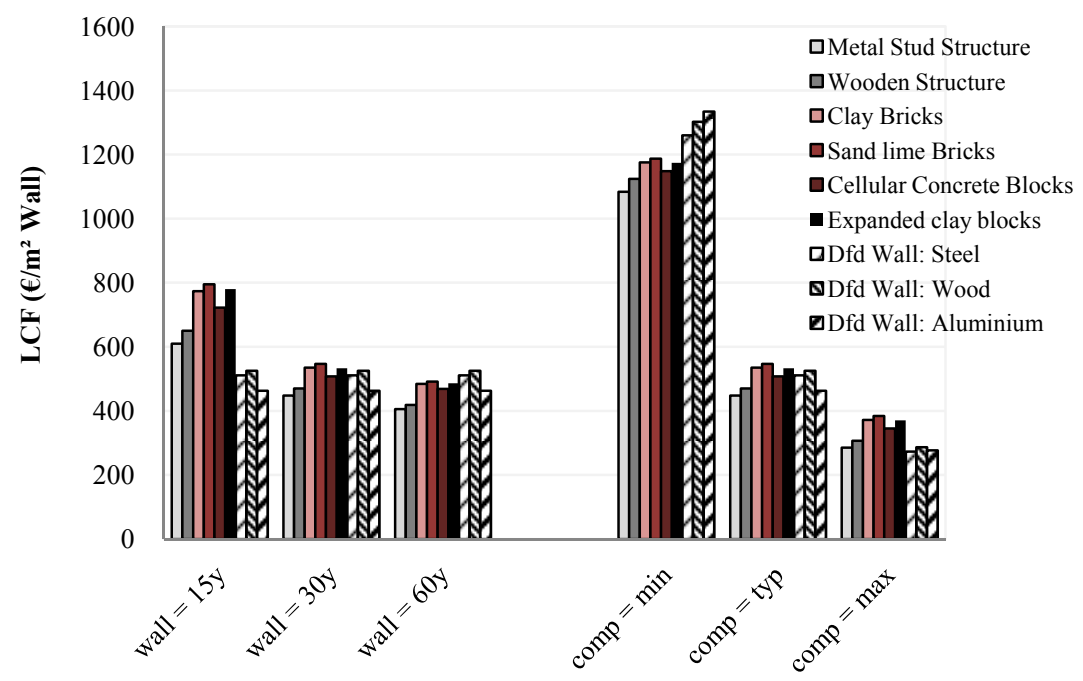

Figure 3: $\quad$ Life cycle financial assessment of wall types.

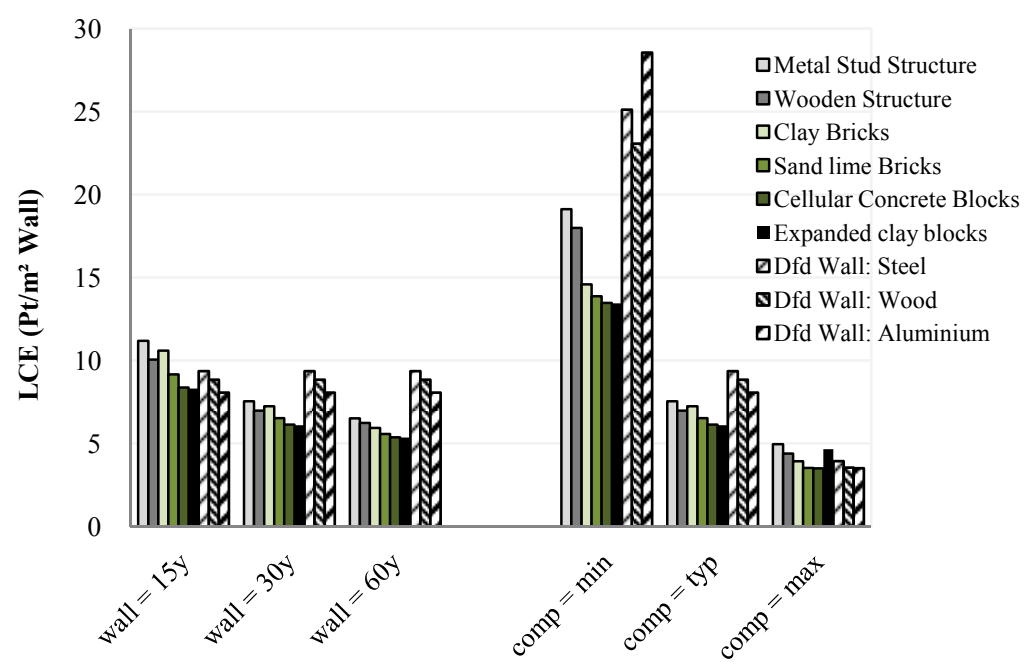

Figure 4: Life cycle environmental assessment of wall types.

First, the rate of internal change must be relatively high, in this case at least 15 years, for its reuse potential and its benefits of deconstruction, to weigh up against the initial higher impact of Dfd walls. Due to the multiple alterations of the wall partitioning, the reference cases must face up against major impacts of each replacement, including entire demolition of the wall and new extraction of raw materials for the production of a new similar wall. In this case, the DfD 
solutions score significantly better than the reference case, that is, between 15$20 \%$ for the financial and the environmental life cycle assessment.

\subsubsection{Quality of the components and work execution level}

On the other hand, specific conditions such as the quality of the component and the work execution level of the components can drastically decrease their expected technical service life. Attempts of reuse strategies to extend the material's useful life then cannot be fully taken advantage of. This explains why in the short component scenario the DfD designed walls have a higher financial and environmental impact than the reference walls. On the contrary, when a maximised technical service life of components can be achieved, the reuse benefits can be more developed and thus, the DfD solutions score better.

To make Design for Deconstruction successful attention should be given to the correct choice of materials including a long technical service life, to prolong the usability and thus make them more profitable. The good quality of the execution on the construction site is of crucial importance.

\subsubsection{Labour cost}

Another identified barrier for dynamic re-design is the extensive amount of labour involved. Since labour cost contributes for over $50 \%$ in the total life cycle cost (see Figure 5), this is an important factor for this analysis.

The dimensions (amount, size and weight) of wall components are an important factor in the total labour cost. Since the use of multiple small components implies longer assembly times, the labour cost will increase. This explains why the masonry walls, with many small components, have a higher labour cost than the dry walls, as represented in Figure 5.

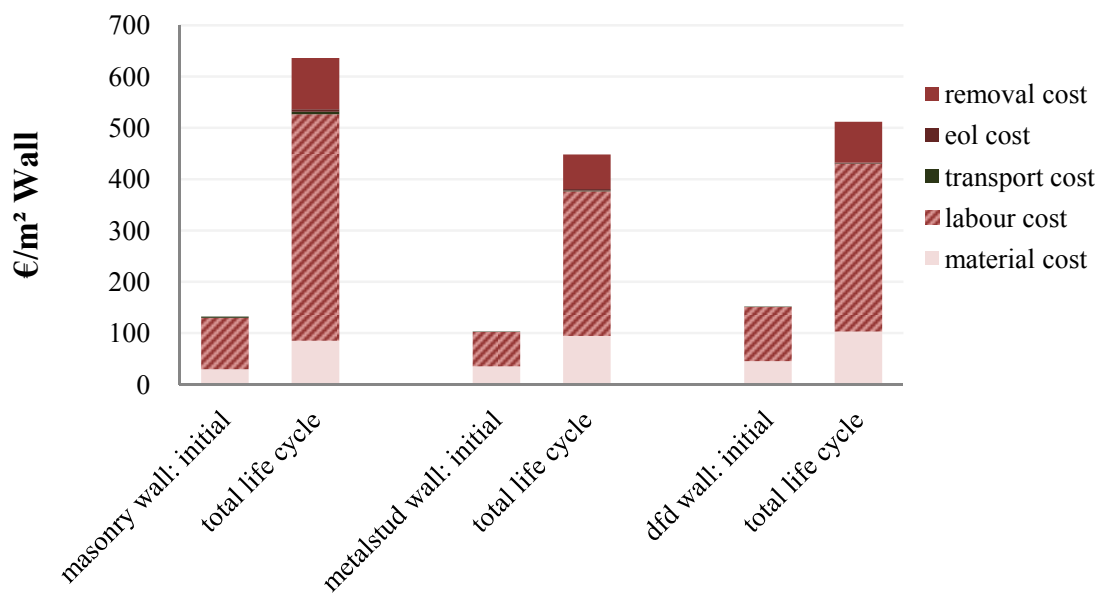

Figure 5: $\quad$ Financial life cycle costs of 3 wall types. 
On the other hand, design for disassembly and deconstruction demands more complex connections, which likewise increases the assembly cost compared to dry walls, as seen in Figure 5. The labour cost when using abundant number of connections elements such as bolts and screws in fact have negative cost effects. Additionally, at the end-of life stage, removing and separating building materials costs more compared to the actual value for reuse.

Still, threat of limited landfill space in the future, rising tipping fees, and increased environmental pressures necessitate a solution. Deconstruction for reuse and transformation potential is a better alternative to demolition, primarily in its consistency with recent trends in environmental life-cycle awareness [12].

\section{Conclusions}

When applied on the right renovation projects and under the right circumstances, design for deconstruction and disassembly can be environmentally and financially advantageous for wall partitioning. A right selection in each renovation project should be made, evaluating which building layers have a high rate of alteration, or estimating which building layers are expected to need future upgrading. However, need for change is never predictable, and thus, when assessment of DfD approach for a building layer reveals that it is viable in environmental and financial terms, even in building layers with a low change rate, it is always safer to introduce DfD design. In that way, unpredictable needs can still be responded without taking part in the environmental degradation.

Since the service life of building layers has been identified to be a major key player, different scenarios must always be assessed considering alternative renovation proposals. A short service life of the considered building layer makes DfD solutions viable in both environmental and financial terms, since many alterations will be needed over the life cycle, and the extended useful lives reuse potential of DfD designed assemblies can be fully taken advantage of. For building layers that do not have a high rate of change DfD solutions are not always desirable since they can create higher life cycle costs and impacts. Each situation therefore has to be assessed to make sure if DfD solutions are required.

A barrier for deconstruction and disassembly nowadays is the high labour cost involved. As tools and techniques for deconstruction improve, and subsequently productivity improves, labour costs should see a reduction in the near future [12]. With these improvements, in time deconstruction techniques will become more competitive with demolition practice [13].

\section{References}

[1] UN-HABITAT, The State of the World's Cities 2008/2009: Harmonious Cities, Earthscan, London, 2008.

[2] State of the World 2009 - Into a Warming World, The Worldwatch Institute, 2009. 
[3] Thormark, C., A low energy building in a life cycle - its embodied energy, energy need for operation and recycling potential, Building and Environment, 37, pp. 429-435, 2002.

[4] Thormark, C., The effect of material choice on the total energy need and recycling potential of a building, Building and Environment, 41, pp.10191026, 2006.

[5] Debacker, W. et al., 4 Dimensional design: From strategies to cases Generation of fractal grammar for reusing building elements, International Journal of Ecodynamics 2007: 258 - 277, 2007.

[6] Debacker, W., Design and environmental load assessment of multi-use construction kits for temporary applications based on 4Dimensional Design, PhD diss., Faculty of Engineering Sciences, Department of Mechanics of Materials and Constructions, Vrije Universiteit Brussel, 2008.

[7] Allacker, K., Sustainable Building: The development of an evaluation method, PhD diss, Faculty of Engineering Sciences, Department of Architectural Engineering, Katholieke Universiteit Leuven, 464p., 2010.

[8] ISO 14040, Environmental management - Life cycle assessment Principles and framework, 20p, 2006.

[9] Eco-indicator, www.pre.nl/eco-indicator99.

[10] Durmisevic, E., Transformable Building Structures, PhD diss, Faculty of Architectural Engineering, Technical University Delft, 305 p., 2006.

[11] ISO 15686, Buildings and constructed assets: Service life planning- Part 1, International Organisation for Standardisation, 41p, 2000.

[12] Endicott, B., et al., Research on Building Deconstruction, Final Project Report, University of California Berkley, 36p, 2005.

[13] Greer, D., Building the Deconstruction Industry, Biocycle, p 36-42, 2004. 